\title{
Factors Influencing Students' Behavior Toward Trash Classification
}

\author{
Hau Van Pham, Loc Son Tang, Hanh Thi Hai Nguyen, and Hue Thi Hoang
}

\begin{abstract}
Trash classification plays an important role in enhancing people's awareness of protecting environment. This study aimed to evaluate factors influencing students' behavior toward trash classification in Vietnam. Six dimensions used in this study were: Knowledge, Attitude, Perceived Effective Behavior, Subjective Standards, Habits and Infrastructure. The research conducted a survey with participation of 274 respondents. The data was analyzed by using descriptive statistics, factor analysis and regression.
\end{abstract}

Index Terms-Trash classification; Students; Knowledge, Attitude; Perceived Effective Behavior; Subjective Standards; Habits and Infrastructure.

\section{INTRODUCTION}

Trash classification is recently one of the priority concerns of many countries all over the world. There are many global issues relating to environment such as global warming, greenhouse effect or desertification. These environmental issues are always mentioned by governments and people in the world as an extremely disturbing, and concerning issue in all aspects of life.

Trash classification plays an extremely important role that positively affects social and environmental life of a country. Since countries grow, pressure under over population and economy on trash will become a serious problem. Therefore, in terms of developed countries in general, and developing countries like Vietnam in particular, we must have a vision and strategy on trash treatment. Although the trash is dramatically increasing, the treatment is still difficult, but this is an extremely rich source of renewable materials.

Traditionally, people would think that classifying household trash is a time-consuming and labor-intensive task. However, that study pointed out a completely opposite experiment, Polish people considered trash classification as a work in their favor, they classified trash in every way possible. For Asian countries, Singapore - an island nation famous for its cleanliness, or Korea has made tremendous strides in the environment. Koreans have thought about using trash treatment technology to recycle them into useful products, promoting economic development since 2004. Typically, a research paper on "Methods of recycling oyster shells to control water sources" discussed the method of pyrolysis of trash oysters in thermal conditions [4]. The

Published on April 16, 2020.

Hau Van Pham, National Economics University, Vietnam.

(e-mail: phamhau100598@gmail.com).

Loc Son Tang, National Economics University, Vietnam.

(e-mail: loctangneu@gmail.com).

Hanh Thi Hai Nguyen, National Economics University, Vietnam.

(corresponding e-mail: nguyen.hanh@neu.edu.vn).

Hue Thi Hoang, National Economics University, Vietnam.

(e-mail: hoanghue@neu.edu.vn). appropriate degree and pressure will transform this material into a drug to remove up to $98 \%$ of the phosphate in domestic sewage. A study showed how to recycle circuit boards by vacuum pyrolysis and turn them into gases, liquids used as raw materials or chemical resources [9]. From the aforementioned studies, developed countries paid great attention to trash classification through their research, academic debate seminars, and methods to recycle trash become raw materials, gas and vice versa for social purposes and economic development.

Trash classification is still a new definition for the majority of Vietnamese people and the habit of trash classification in Vietnam is almost completely absent. Empirical evidence shows that, after government issued regulations on the classification of domestic solid trash, there are still many people got violations. Trash classification is an urgent task and needs to be scaled up, but trash classification has not been studied in detail, specifically the factors affecting on.

This study goes into research on students' trash classification behavior in Vietnam. In addition, we also hope that this paper will make a positive contribution to environmental issues in Vietnam.

\section{LITERATURE REVIEW}

Trash classification can be defined as a cycle in which trash is divided into different parts depending on the purpose of using trash. Currently, there are many ways to classify rubbish and the most common of which are manual classification and mechanical classification.

A study showed that recycling household trash depends on the level of awareness and knowledge about recycling [13]. A research also mentioned the appropriate knowledge for recycling in their research [14]. In addition, Knowledge applied as an influential variable [20]. The intention to classify trash is a variable that depends on the habit includes environmental protection habits such as throwing trash in the right place, recycling habits, the habit of using items many times. According to a study pointed contribution of previous recycling behavior and recycling habits were also been considered [3]. Also a study showed that lack of habit is the reason for the failure to classify household recycling trash [2]. Previous behaviors and lack of habits all contributed significantly to recycling intention. Facilities are considered an important variable in assessing students' intentions and trash classification behavior. Improving the signs and classifying trash in appropriate places would improve recycling behavior of students on campus [17].

In addition, TPB model and logit regression method were used, which illustrated the convenience of recycling facilities and services is one of four factors that determines 
the willingness and behavior of people in Beijing in recycling electronic trash [23]. In addition, a study showed the influence of facilities on intentions and classifying and recycling behavior [18]. The study suggested economic benefits were a vital component in assessing the behavior of e-trash recycling in Beijing [23].

In many studies related environmental issues, Ajzen's behavioral theoretical model has always been preferred to use [5]. His model was first proposed in 1980, and then he and Fishbein were studied in 2005. Specifically, the model has made 3 hypotheses as follows:

Hypothesis 1: Intention is influenced by attitudes to behavior, subjective standards and perceived effectiveness.

Hypothesis 2: Intention is a big factor in predicting behavior.

Hypothesis 3: Between intention and behavior, there is always a gap affected by factors and factors that could promote or hinder behavior.

\section{Methodology}

\section{Theoretical Framework}

The theory model of [5] is very suitable for the topic of classification behavior, the research authors decided to choose this model for our research. According to all the above dependent and independent factors, this research has two regression models. The first model shows the relationship between Intention and variables: Knowledge, Attitude, Perceived effective behavior, Subjective standards, Habits, and Infrastructure. The second model shows the relationship between Intention and Behavior.

The first regression model:

$$
\mathbf{a}_{6} \mathrm{UF}+\mathbf{e}(\mathrm{IT})
$$$$
\mathbf{I T}=\mathbf{a}_{0}+\mathbf{a}_{1} \mathbf{A T}+\mathbf{a}_{2} \mathbf{S N}+\mathbf{a}_{3} \mathbf{P E B}+\mathbf{a}_{4} \mathbf{K N}+\mathbf{a}_{5} \mathbf{H B}+
$$

In which:

$\mathrm{a}_{0}$ : Intercept

a1, a2, a3, a4, a5, a6: Slope coefficient

e: residual

- The second model:

$\mathbf{B H}=\mathbf{b}_{0}+\mathbf{b}_{1} \mathbf{I T}+\mathbf{e}(\mathbf{B H})$

In which:

a0: Intercept

$\mathrm{a}_{1}$ : Slope coefficient

e: Residual

\section{Data collection}

The research selected the sampling error of $6 \%$, and used the sampling formula proposed by [10] as follows:

$$
\mathrm{N}=\frac{\mathrm{N}}{1+\mathrm{N} \mathrm{a}^{2}}
$$

In which a is the sampling error we have taken is $6 \%, \mathrm{~N}$ is the total number of students in the school. The research team takes $\mathrm{N}$ approximately 22,000 thousand students. The sample size is 274 students.

Most of the questions in the survey were designed based on five-point Likert scale. The questionnaire was designed based on seven points Likert scale with 2 highest levels of 1 and 7 respectively with "strongly disagree" "and strongly agree".

The team used SPSS 25.0 software to analyze the statistics describing the variables.
TABLE I: SUMMARY OF INDEPENDENT VARIABLES

\begin{tabular}{|l|l|l|l|l|l|}
\hline STT & \multicolumn{1}{|c|}{ Factors } & Min & Max & Mean & $\begin{array}{c}\text { Standard } \\
\text { deviation }\end{array}$ \\
\hline 1 & Intention (IT) & 1 & 7 & 4.5438 & 1.265 \\
\hline 2 & Behavior (BH) & 1 & 7 & 3.6584 & 1.1444 \\
\hline 3 & Attitude (AT) & 1 & 7 & 6.0633 & 1.0487 \\
\hline 4 & Knowledge (KN) & 1 & 6.75 & 4.3741 & 1.0667 \\
\hline 5 & Habits (HB) & 1 & 7 & 4.3467 & 1.3809 \\
\hline 6 & Standard Norm (SN) & 1 & 6.5 & 3.3312 & 1.1264 \\
\hline 7 & $\begin{array}{l}\text { Perceived effective } \\
\text { behavior }\end{array}$ & 1 & 7 & 5.8677 & 1.0667 \\
\hline
\end{tabular}

Regression analysis 1:

\begin{tabular}{|c|c|c|c|c|c|}
\hline $\mathrm{R}^{2}$ & $\begin{array}{l}\text { Adjusted } \\
\mathrm{R}^{2}\end{array}$ & Durbin-Watson & Estimated error & & \\
\hline 0.510 & 0.499 & 2.030 & 0.89558 & & \\
\hline \multicolumn{2}{|c|}{ Factors } & $\begin{array}{c}\text { Regression } \\
\text { coefficient not } \\
\text { yet standardized }\end{array}$ & $\begin{array}{l}\text { Standardized } \\
\text { regression } \\
\text { coefficient }\end{array}$ & Sig & VIF \\
\hline \multicolumn{2}{|c|}{ Intercept (a0) } & -0.134 & & 0.704 & \\
\hline \multicolumn{2}{|c|}{ Attitude (AT) } & 0.141 & 0.177 & 0.044 & 2.000 \\
\hline \multicolumn{2}{|c|}{$\begin{array}{l}\text { Standard norm } \\
\text { (SN) }\end{array}$} & 0.177 & 0.158 & 0.010 & 1.990 \\
\hline \multicolumn{2}{|c|}{$\begin{array}{l}\text { Perceived effective } \\
\text { behavior (PEB) }\end{array}$} & 0.163 & 0.137 & 0.024 & 1.996 \\
\hline \multicolumn{2}{|c|}{ Knowledge (KN) } & 0.018 & 0.015 & 0.787 & 1.733 \\
\hline \multicolumn{2}{|c|}{ Habits (HB) } & 0.095 & 0.103 & 0.076 & 1.828 \\
\hline \multicolumn{2}{|c|}{ Infrastructure (IF) } & 0.460 & 0.407 & 0.000 & 1.783 \\
\hline
\end{tabular}

TABLE I: REGRESSION ANALYSIS RESULT 1

Except for knowledge variables, the remaining variables all have sig $<0.05$, so we have the following regression function

$$
\mathrm{IT}=-0.314+0.141 \mathrm{AT}+0.177 \mathrm{SN}+0.163 \mathrm{PEB}+
$$

$0.095 \mathrm{HB}+0.46 \mathrm{IF}+\mathrm{e}(\mathrm{IT})$

Adjusted R-Square (adjusted $\mathrm{R}^{2}$ ) $=0.499$, all independent variables explain $49.9 \%$ of the variation of Intention - Model 1 can be applied to predict Intention of College students. 
Regression analysis 2:

TABLE I: REGRESSION ANALYSIS RESULT 2

\begin{tabular}{|c|c|c|c|c|}
\hline \multicolumn{1}{|c|}{$\mathrm{R}^{2}$} & Adjusted $\mathrm{R}^{2}$ & Estimated error & \multicolumn{2}{|c|}{} \\
\hline 0.628 & 0.627 & 0.69940 & \multicolumn{2}{|c|}{ Sig } \\
\hline \multicolumn{1}{|c|}{ Factors } & $\begin{array}{c}\text { Regression coefficient not } \\
\text { yet standardized }\end{array}$ & $\begin{array}{c}\text { Standardized } \\
\text { regression } \\
\text { coefficient }\end{array}$ & 0.012 \\
\hline Intercept(b0) & 0.401 & 0.792 & 0.000 \\
\hline $\begin{array}{l}\text { Intention } \\
\text { (IT) }\end{array}$ & 0.717 & & \\
\hline
\end{tabular}

With the significance level of 0.05 ; model 2 has an Intercept $\left(\mathrm{b}_{0}\right)$ and the factor Intention (IT) is statistically significant because their sig are 0.012 and 0.000 respectively, are less than 0.05 . Therefore, the Intention is major factor affecting the Behavior $(\mathrm{BH})$ of the college students in practice.

+ Adjusted $\mathrm{R}^{2}=0.627$, Intention (IT) explains up to $62.7 \%$ of the variation of Behavior $(\mathrm{BH})$. This model is applicable for practical use.

The regression equation is:

$\mathrm{BH}=0.401+0.717 \mathrm{IT}+\mathrm{e}(\mathrm{BH})$

\section{Data Analysis And Discussion}

In the first regression model, with the standardized regression coefficients of factors Infrastructure (IF), Standard Norm (SN), Perceived effective behavior respectively is $0.407 ; 0,158$ and 0,137 , therefore, the biggest factor influencing the "intention to classify trash" of College students is the Infrastructure. After that, the second most influential variable is the Standard Norm the impact of society, the surrounding people is a factor affecting the "intention to classify trash". Finally, it is the impact due to the awareness of effective behavior, if they are aware that trash classification is a good thing for the environment and society, their Intention will increase.

In the second model, $\mathrm{b} 1=0.717$, this indicates that if the Intention (IT) is increased by 1 unit, the Behavior (BH) increases to 0.717 units. This shows that the intention has a great impact on trash classifying behavior.

According to the survey results, students of the College have good awareness, knowledge and thoughts on the issues surrounding trash classifying and treatment. They have a very high Attitude, Perceived effective behavior at 6.0633 and 5.8677, two factors with lower mean are Intention and Knowledge, 4.5438 and 4.3741 respectively. Besides, they also have good environmental protection Habits with an average of 4.3467. However, the Standard Norm is low (3.3312). This shows that trash classification is not popular in Vietnam and more accurately in Hanoi. It is also worth noting that the behavior of trash classifying by National Economics students is quite different from their intention to classify trash. This shows us that the intention to classify rubbish is only an important factor affecting students' trash classification behavior.

Testing related to Infrastructure and incentives shows that, on average, the Infrastructure for classifying trash are low. When analyzing the factors that influence students on trash classifying Behavior, we see that the Intention to classify trash is an important variable with great impact.

Based on these analyses, the research team made several recommendations:

- Improve the Infrastructure for trash separation on campus by having more segregated trash bins, placing them in places where many students travel, places that are easy to see and convenient for trash disposal.

- Raising awareness, attitudes, and knowledge about trash classification by having banners, boards mentioning the benefits that trash classification brings to the environment and society.

- Establishing environmental clubs, encouraging students to participate in, and organizing campus cleaning sessions to enhance students' environmental protection habits.

- Awarding incentives and rewards if individuals and collectives classify and recycle trash for environmental protection.

\section{REFERENCES}

[1] A. Omran, A. Mahmoud, A. H. Abdul, and G. M. Robinson, "Investigating households attitude toward recycling of solid waste in Malaysia: a case study", pp. 275-288, 2009.

[2] C. Knussen, and F. Yule, "I'm Not in the Habit of Recycling" The Role of Habitual Behavior in the Disposal of Household Waste", Environment and Behavior, vol. 40, no. 5, pp. 683-702, 2008.

[3] C. Knussen, F. Yule, J. MacKenzie, and M. Wells, "An analysis of intentions to recycle household waste: The roles of past behaviour, perceived habit, and perceived lack of facilities", Journal of environmental psychology, vol. 24, no. 2, pp. 237-246, 2004.

[4] H. B. Kwon, C. W. Lee, B. S. Jun, S. Y. Weon, and B. Koopman, "Recycling waste oyster shells for eutrophication control", Resources, Conservation and Recycling, vol. 41, no. 1, pp. 75-82, 2004.

[5] I. Ajzen, “ Martin Fishbein's legacy: The reasoned action approach”, The Annals of the American Academy of Political and Social Science, vol. 640 , no. 1 , pp. 11-27, 2012.

[6] J. K. Ford, R. C. MacCallum, and M. Tait, "The application of exploratory factor analysis in applied psychology: A critical review and analysis", Personnel psychology, vol. 39, no. 2, pp. 291-314, 1986.

[7] K. Chan, "Mass communication and pro-environmental behaviour: waste recycling in Hong Kong", Journal of environmental management, vol. 52, no. 4, pp. 317-325, 1998.

[8] L. Darby, and L. Obara, "Household recycling behaviour and attitudes towards the disposal of small electrical and electronic equipment", Resources", Conservation and Recycling, vol. 44, no. 1, pp. 17-35, 2005.

[9] L. Long, S. Sun, S. Zhong, W. Dai, J. Liu, J., and W. Song, "Using vacuum pyrolysis and mechanical processing for recycling waste printed circuit boards", Journal of Hazardous Materials, vol. 177, no. 1-3, pp. 626-632, 2010.

[10] L. S. Aiken, S. G. West, and R. R. Reno, Multiple regression: Testing and interpreting interactions, Sage, 1991.

[11] M. Czajkowski, T. Kądziela, and N. Hanley, "We want to sort! Assessing households' preferences for sorting waste", Resource and energy economics, vol. 36, no. 1, pp. 290-306, 2014.

[12] M. P. Zanna, B. T. Johnson, and D. Albarracin, The handbook of attitudes, 2005.

[13] M. Tonglet, P. S. Phillips, and A. D. Read, “ Using the Theory of Planned Behaviour to investigate the determinants of recycling behaviour: a case study from Brixworth, UK", Resources, conservation and recycling, vol. 41, no. 3, pp. 191-214, 2004.

[14] M. Tonglet, P. S. Phillips, and M. P. Bates, "Determining the drivers for householder pro-environmental behaviour: Waste minimisation compared to recycling", Resources, conservation and recycling, vol. 42, no. 1, pp. 27-48, 2004. 
[15] P. Y. Chu, and J. F. Chiu, "Factors influencing household waste recycling behavior: Test of an integrated model 1", Journal of Applied Social Psychology, vol. 33, no. 3, pp. 604-626, 2003.

[16] L. Vining, and A. Ebreo, " Predicting recycling behavior from global and specific environmental attitudes and changes in recycling opportunities 1", Journal of applied social psychology, vol. 22, no. 20, pp. 1580-1607, 1992.

[17] T. C. Kelly, I. G. Mason, M. W. Leiss, and S. Ganesh, "University community responses to on-campus resource recycling", Resources, Conservation and Recycling, vol. 47, no. 1, pp. 42-55, 2006.

[18] R. E. Timlett, and I. D. Williams, "The impact of transient populations on recycling behaviour in a densely populated urban environment", Resources, Conservation and Recycling, vol. 53, no. 9, pp. 498-506, 2009.

[19] R. T. LaPiere, "Attitudes vs. actions", Social forces, vol. 13, no. 2, pp. $230-237,1934$

[20] S. Oskamp, M. J. Harrington, T. C. Edwards, D. L. Sherwood, S. M. Okuda, and D. C. Swanson, "Factors influencing household recycling behavior", Environment and behavior, vol. 23, no. 4, pp. 494-519, 1991.

[21] S. Barr, "Factors influencing environmental attitudes and behaviors: A UK case study of household waste management", Environment and behavior, vol. 39, no. 4, pp. 435-473, 2007.

[22] S. Lee, and H. S. Paik, "Korean household waste management and recycling behavior", Building and Environment, vol. 46, no. 5, pp. 1159-1166, 2011.

[23] Z. Wang, B. Zhang, J. Yin, and X. Zhang, “Willingness and behavior towards e-waste recycling for residents in Beijing city, China", Journal of Cleaner Production, vol. 19, no. 9-10, pp. 977984, 2011

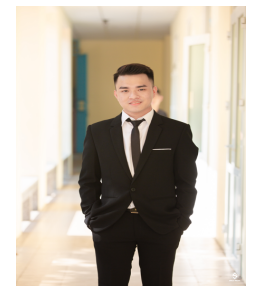

Author 1: Hau Van Pham

Email: phamhau100598@gmail.com

Present work status: Student

Department name: Faculty of Management Science

Institution name: National Economics University,

Hanoi, Vietnam

Author 2: Loc Son Tang

Email: loctangneu@gmail.com

Present work status: Student

Department name: Faculty of Management Science

Institution name: National Economics University, Hanoi, Vietnam

Author 3: Hanh Thi Hai Nguyen (Corresponding author)

Email: nguyen.hanh@neu.edu.vn

Present work status: Lecturer

Department name: Faculty of Human Resources Economics and Management

Institution name: National Economics University, Hanoi, Vietnam

Author 4: Hue Thi Hoang

Email: hoanghue@neu.edu.vn

Present work status: Lecturer

Department name: Faculty of Human Resources Economics and Management

Institution name: National Economics University, Hanoi, Vietnam 